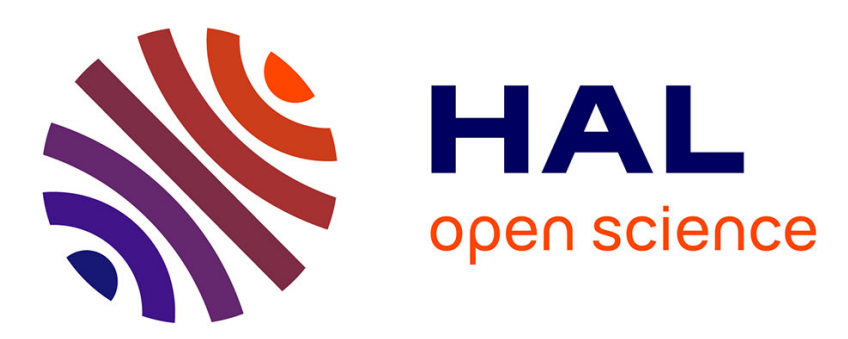

\title{
Influence of joint angle on muscle fascicle dynamics and rate of torque development during isometric explosive contractions
}

Robin Hager, Thomas Poulard, Antoine Nordez, Sylvain Dorel, Gaël Guilhem

\section{- To cite this version:}

Robin Hager, Thomas Poulard, Antoine Nordez, Sylvain Dorel, Gaël Guilhem. Influence of joint angle on muscle fascicle dynamics and rate of torque development during isometric explosive contractions. Journal of Applied Physiology, 2020, 129 (3), pp.569-579. 10.1152/japplphysiol.00143.2019 . hal03298460

\section{HAL Id: hal-03298460 \\ https://hal.science/hal-03298460}

Submitted on 4 Aug 2021

HAL is a multi-disciplinary open access archive for the deposit and dissemination of scientific research documents, whether they are published or not. The documents may come from teaching and research institutions in France or abroad, or from public or private research centers.
L'archive ouverte pluridisciplinaire HAL, est destinée au dépôt et à la diffusion de documents scientifiques de niveau recherche, publiés ou non, émanant des établissements d'enseignement et de recherche français ou étrangers, des laboratoires publics ou privés. 


\section{Influence of joint angle on muscle fascicle dynamics and rate of torque}

2 development during isometric explosive contractions

3

4 Running title: Muscle-tendon interactions and explosive strength

6 Robin HAGER ${ }^{1}$, Thomas POULARD ${ }^{2}$, Antoine NORDEZ ${ }^{2,3}$, Sylvain DOREL ${ }^{2}$,

\section{Gaël GUILHEM ${ }^{1} *$}

$8 \quad{ }^{1}$ French Institute of Sport (INSEP), Research Department, Laboratory Sport, Expertise and

9 Performance (EA 7370), Paris, France

10 2Laboratory "Movement, Interactions, Performance" (EA 4334), Faculty of Sport Sciences,

11 University of Nantes, Nantes, France

$12{ }^{3}$ Health and Rehabilitation Research Institute, Faculty of Health and Environmental Sciences,

13 Auckland University of Technology, Auckland, New Zealand

14

15

16

17

27 Keywords: explosive strength; muscle-tendon interactions; ultrafast ultrasound; muscle 28 activation; force-velocity properties

*Correspondence and reprints:

Gaël Guilhem

Institut National du Sport, de l'Expertise et de la Performance

Laboratoire Sport, Expertise et Performance (EA 7370)

11, avenue du Tremblay

75012 Paris

France

Tel: +33(0)141744336

Fax: +33 (0)141754535

e-mail: gael.guilhem@,insep.fr

26 


\section{ABSTRACT}

30 This study investigated how joint angle influences fascicle shortening dynamics of 31 gastrocnemius medialis (GM) during explosive contractions, and the resulting impact on rate 32 of torque development (RTD). Sixteen participants performed six sets of five maximal 33 explosive voluntary isometric plantar flexions at $-20^{\circ},-10^{\circ}, 0^{\circ}$ (neutral position), $10^{\circ}, 20^{\circ}$ and $3430^{\circ}$ of ankle angle, and five no-load ballistic plantar flexions. RTD assessed over all time 35 windows (from 0 to $200 \mathrm{~ms}$ ) was significantly lower in extreme plantar flexed $\left(\geq 20^{\circ}\right)$ and 36 dorsiflexed $\left(-20^{\circ}\right)$ positions compared to $-10,0^{\circ}\left(475 \pm 105 \mathrm{Nm} \cdot \mathrm{s}^{-1}\right)$ and $10^{\circ}$. At these neutral 37 positions, RTD was maximal and muscle fascicles mainly operated over the plateau of the force-length relationship. At $0^{\circ}$, fascicle shortening velocity peaked at $9.26 \pm 2.85 \mathrm{~cm} . \mathrm{s}^{-1}$ (i.e.,

$3928.2 \%$ of maximal shortening velocity measured during no-load ballistic condition). At 112 $40 \mathrm{~ms}$ after RTD onset, fascicle force reached $208 \pm 78 \mathrm{~N}$ (i.e., $85.6 \%$ of the theoretical 41 maximum force at the corresponding shortening velocity) and was thereafter comprised 42 within the $95 \%$ confidence interval of the force-velocity curve. This clearly indicates that 43 muscle force reached the maximal force that accounts for the fascicle shortening velocity. 44 These findings suggest that the dynamic behavior of muscle fascicles, and the associated 45 fascicle shortening velocity, may influence the rapid force-generating capacity mainly from $46100 \mathrm{~ms}$ of RTD onset. The present study provides important information to better understand 47 the determinants of human muscle performance during explosive tasks. 
- Ankle angle influences the operating muscle fascicle lengths of gastrocnemius medialis, and the rate of torque development during explosive isometric plantar flexions.

- The rate of torque development peaks in neutral angles where muscle fascicles shorten over the plateau of the force-length relationship.

- When fascicles operate over the plateau of the force-length relationship (neutral ankle positions), the force-velocity properties represent a limiting factor for the rapid forcegenerating capacity from $100 \mathrm{~ms}$ after the onset of explosive contractions. 


\section{INTRODUCTION}

The ability of the human skeletal muscle to achieve maximal force production as quickly as possible is important for actions that involve explosive tasks or rapid adjustments in postural balance such as those encountered in sport-specific movement $(1,8,37,43)$. This capacity to produce explosive force is classically evaluated through the rate of torque development (RTD) achieved during a maximal voluntary isometric contraction $(1,30)$. RTD can be measured using a relatively simple setting (i.e., a force or torque sensor) as the variations of torque (or force) over various periods of time from the onset of torque $(0 \mathrm{~ms})$ to $50-200 \mathrm{~ms},(19,44)$. Thus, RTD is widely used as a performance index in various populations (i.e., athletes, elderly, patients) and sports where the amount of time available for an increase in force is limited (e.g., athletics, team sports, combat sports) $(37,43,49)$.

It is well established that RTD depends primarily on the neural system's ability to maximally and rapidly activate the available pool of motor units $(15,19)$. In particular, it has been recently shown that the motor neuron recruitment speed and the maximal rate at which motor neurons discharge action potentials in the initial phase of the contraction $(0-50 \mathrm{~ms})$ dictate the variability in RTD (16). Alternatively, additional factors, such as muscle fiber-type composition, architecture, muscle and tendon elastic properties have been suggested to influence $\operatorname{RTD}(5,37,52,53)$. In a recent study, Massey et al. (40) reported small correlations between muscle-tendon unit relative stiffness and voluntary RTD, but no correlation with absolute and relative tendon stiffness. This demonstrated that other factors than tissue stiffness would influence RTD and confirmed the need for further experimental data to better understand the roles of these variables during voluntary explosive contraction $(22,37,40)$.

One possible explanation of the difficulty to infer the influence of tendon mechanical properties on RTD is the fact that muscle and tendon inherently interact during contractions in vivo. Using ultrasound, several studies demonstrated that muscle fascicle behaviour can be 
83 largely uncoupled from that of the behaviour of the muscle-tendon unit during various human

84 movements thanks to the compliance of tendinous tissues $(12,20)$. As a basic illustration of

85 this process, muscle fascicles were reported to shorten while tendinous tissues lengthen during

86 isometric contractions of increasing intensity (29). This demonstrates that a non-isometric

87 contraction is performed at the fibre level, while the muscle-tendon length remains constant

88 (21, 29). These dynamic interactions between muscle and tendon may thus modify the range

89 of lengths over which muscle fibres operate. A recent study nicely demonstrated that absolute

90 knee extensor RTD was influenced by joint angle due to both alterations in neuromuscular

91 activation and changes in contractile response [i.e., twitch and octet evoked responses; (34)].

92 As recently shown for electrically-evoked contractions, the change in joint angle also

93 influences the initial fascicle length (41). In addition, joint angle could influence the apparent

94 stiffness of series elastic tissues and the interplay between these tissues and fascicles.

95 However, to our knowledge, no study has investigated fascicle dynamics (i.e., length changes)

96 during explosive isometric voluntary contractions. Such measurements may contribute to

97 determine the changes in operating fascicle lengths involved over time during voluntary

98 explosive contractions. Their comparison with force-length and force-velocity relationships

99 could thereby give very important information about their influence on RFD performance

100 (17). In addition, the influence of joint angle was not addressed for plantar flexors, while the

101 long Achilles tendon plays an important role $(23,25)$. If confirmed, such hypothesis may

102 contribute to bring new insights into the significant influence of joint angle on maximal and 103 explosive strength $(14,47)$.

104 The present study aimed to examine the behaviour of gastrocnemius medialis (GM)

105 muscle fascicle during a voluntary RTD test. Maximal explosive isometric contractions of

106 plantar flexor muscles were performed at various ankle positions (from $-20^{\circ}$ in dorsiflexion to

$10730^{\circ}$ of plantar flexion). Given the significant changes in fascicle length reported during 
108 isometric contractions in humans $(21,29,45)$, our objectives were twofold: (i) to determine

109 the influence of ankle angle on the fascicle length shortening and RTD achieved during an 110 explosive contraction; (ii) to investigate how this dynamic behaviour of muscle fascicle and

111 its shortening velocity may influence RTD (by referring to the force-velocity relationship) in a

112 joint configuration that elicits fascicle shortening over the plateau of the force-length 113 relationship.

114

\section{METHODS}

\section{Participants}

117 Ten males and six females (age: $23.2 \pm 2.7$ years, height: $175.3 \pm 6.4 \mathrm{~cm}$, body mass: $70.2 \pm$

$11812.6 \mathrm{~kg}$ ), with no history of ankle disorder or injury, participated in this study. All volunteers

119 were informed about the nature, aims and risks associated with the experimental procedure

120 before giving their written consent to participate. The study was approved by the local ethics 121 committee (2017-A03117-46) and conformed to the standards of the Declaration of Helsinki.

\section{Experimental design}

124 All participants attended one familiarization session and one testing session a few days later.

125 During these sessions, after a 10-minute standardized warm-up, participants performed 5

126 ballistic plantar flexions with no external load (load $=0 \mathrm{~kg})$ on a specific ergometer composed

127 of a specific rotational footplate (Bio2M, Compiegne, France). Participants then performed

128 six sets of five repetitions of explosive voluntary isometric contractions to reach maximal

129 force of the plantar flexor muscles in a randomized order at various ankle angles (from $-20^{\circ}$ in

130 dorsiflexion to $30^{\circ}$ in plantar flexion) on an Eracles-system mechatronic ergometer (Eracles-

131 Technology, Compiègne, France; Fig. 1). RTD and MVC peak torque were assessed on the

132 same repetitions to avoid fatigue occurrence. We performed pilot analyses that showed no 
133 significant difference between these metrics assessed during the same contractions when

134 sufficient time was allowed to the participants were instructed to push "as fast and as hard as 135 possible" with sufficient time (5 s) to then achieve MVC torque plateau (37). We performed

136 pilot analyses that showed no significant difference in peak MCV torque between trials

137 performed in this condition and in a conventional MVC measurement. Therefore, we think

138 that this issue marginally influenced our results. At the end of the protocol, two passive

139 dorsiflexion cycles were performed on the same ergometer at $1^{\circ} . \mathrm{s}^{-1}$ to estimate triceps surae

140 moment arm (see moment arm section) and to subtract the passive torque to the raw torque in

141 order to obtain the active torque to build the active force-length relationship (see data

142 processing). During each explosive contraction performed at each ankle angle (Fig.1),

143 mechanical parameters (i.e., torque, displacement, velocity), muscle fascicle length and

144 velocity of GM, surface electromyography (EMG) activity of gastrocnemius lateralis (GL),

145 soleus (SOL) and tibialis anterior (TA) were simultaneously recorded.

146

\section{Equipment and procedure}

148 Voluntary isometric explosive contractions. Voluntary isometric explosive contractions were

149 performed on an Eracles-system mechatronic ergometer (Eraclès-Technology, Compiègne,

150 France) previously described (23). Participants were placed in prone position, with the knee

151 fully extended ( $0^{\circ}$ : full knee extension) and firmly attached to the ergometer by harness. The

152 axis of right ankle rotation was aligned to the motor axis. The starting position of the ankle

153 was randomly set at various angles: $-20^{\circ},-10^{\circ}, 0^{\circ}, 10^{\circ}, 20^{\circ}$ and $30^{\circ}\left(0^{\circ}\right.$ : foot perpendicular to

154 tibia; positive positions in plantar flexion direction; Fig. 2). Participants were instructed to

155 contract "as fast and hard as possible" in order to reach maximal torque from a relaxed

156 condition (37) after a standardized 3-second countdown with a visual feedback of the force

157 trace and oral feedback of their RTD score measured from 0 to $200 \mathrm{~ms}$ after torque onset. 
158 Five repetitions of 5-s duration interspaced by a 2-min rest period were performed per ankle

159 angle condition, and the 3 best trials were considered for analysis (see below). The residual

160 joint rotation during contractions was measured using a goniometer (Biometrics, Gometz-le-

161 Châtel, France) fixed to the ankle. Since the ergometer was rigid, potential change in ankle

162 angle was due mainly to slight heel movement on the platform. The pre-contraction torque

163 was consistently verified in order to avoid any pre-activation or counter-movement prior to

164 explosive contractions. In the case of pre-tension or countermovement, the trial was discarded

165 from the analysis.

166

167 Passive torque. The passive plantar flexor torque-angle relationship was assessed during the

168 tendon excursion method $(3,35)$ in dorsiflexion direction on the same ergometer and in the

169 same position as for voluntary isometric contractions. Footplate rotation was set at $1^{\circ} \cdot \mathrm{s}^{-1}$ over

170 the maximal range of motion in plantar flexion and dorsiflexion for each individual (i.e., from

$17142 \pm 8^{\circ}$ to $-27 \pm 9^{\circ}$ on average).

172

173 Moment arm. Length of the triceps surae moment arm was measured using the tendon

174 excursion method $(3,39)$ during the measure of passive torque, to determine fascicle force.

175 Displacement of fascicle insertion on deep aponeurosis was observed by ultrasound (32). The

176 length of the triceps surae moment arm was considered as the slope of the linear regression

177 between deep aponeurosis displacement (in $\mathrm{cm})$ and change in ankle angle $\left(-10^{\circ}\right.$ to $20^{\circ} ; \mathrm{r}^{2}=$

$178 \quad 0.99 \pm 0.04)$.

179

180 No-load ballistic contraction. In order to determine maximal fascicle shortening velocity

$181\left(\mathrm{~V}_{\mathrm{max}}\right)$, participants performed maximal dynamic plantar flexions with no external load on a

182 specific ergometer composed of a rotational footplate and a bench (Bio2M, Compiègne, 
183 France) (33) as previously described and used $(24,25)$. The starting position of the ankle was

184 set at $-20^{\circ}$ of dorsiflexion. Participants were instructed to contract "as fast as possible" from

185 rest over the whole range of motion (i.e., $50^{\circ}$ ). Participants performed five trials with a rest of

1861 ' between repetitions. When they thought they could achieve a faster movement, an

187 additional trial was performed, with a maximum of 10 trials to avoid fatigue. The fascicle

188 shortening velocity reached during RTD was expressed relatively to $\mathrm{V}_{\max }$.

189

\section{Data collection and processing}

191 Mechanical data. Joint angle, angular velocity and torque were recorded at $2000 \mathrm{~Hz}$ using an 192 analog-to-digital converter designed by our laboratory (Custom DT, INSEP, Paris, France).

193 Mechanical signals were analysed using custom-written scripts (Origin 9.1, OriginLab

194 corporation, USA). First, signals were low-pass filtered $\left(150 \mathrm{~Hz}\right.$, zero-lag $4^{\text {th }}$ order

195 Butterworth). Then, we determined the onset of contraction during RTD using the torque

196 signal according to the systematic approach proposed by Tillin et al. (51). The onset of torque

197 production was manually determined as previously described by Tillin et al. (49) before low-

198 pass filtering. First, recordings where the baseline (resting) torque was not stable (i.e., $>0.5$

199 N.m the preceding $100 \mathrm{~ms}$ ) were discarded. Second signals were checked with a consistent

200 scale (e.g. $500 \mathrm{~ms}$ vs. $1 \mathrm{~N}$ ). Third, the investigator placed manually a dashed line on the apex

201 of the last peak/trough before the signal deflected from the baseline noise. RTD was

202 calculated as the rising torque divided by the time windows [i.e., a straight line: from 0 to 200

$203 \mathrm{~ms}\left(\mathrm{RTD}_{0-200}\right)$, from 0 to $50 \mathrm{~ms}\left(\mathrm{RTD}_{0-50}\right)$ from 50 to $100 \mathrm{~ms}\left(\mathrm{RTD}_{50-100}\right)$, and from 100 to

$\left.204200 \mathrm{~ms}\left(\mathrm{RTD}_{100-200}\right)\right]$. Mean displacement of the heel was monitored using an electronic

205 goniometer (Biometrics, Gometz-le-Châtel, France). The mean displacement was measured at

206 respectively $1 \pm 1^{\circ}, 1 \pm 1^{\circ}, 1 \pm 2^{\circ}, 2 \pm 2^{\circ}, 2 \pm 2^{\circ}$ and $2 \pm 2^{\circ}$ at respectively $30^{\circ}, 20^{\circ}, 10^{\circ}, 0^{\circ},-$

$20710^{\circ}$ and $-20^{\circ}$. When detachment of the heel was above $5^{\circ}$, the trial was not considered. For 
each set of five contractions performed at a given starting angle, the three trials resulting in

209 the highest $\mathrm{RTD}_{0-200}$ were averaged for further analysis. The peak torque corresponded to the

210 highest peak torque value obtained among the five explosive isometric contraction performed

211 in each ankle angle position. Maximal angular velocity during the no-load condition

212 corresponded to the averaged value measured from $-10^{\circ}$ to $20^{\circ}$ of plantar flexion (25).

213

214 Ultrasound. An ultrafast ultrasound scanner (Aixplorer, Supersonic Imagine, Aix en

215 Provence, France) coupled with a linear transducer array (4-15 MHz, SuperLinear 15-4,

216 Vermon, Tours, France) was used to acquire ultrasonic raw data from the GM muscle at a

217 sampling frequency of $1000 \mathrm{~Hz}$ for RTD and $2000 \mathrm{~Hz}$ for the no-load condition. The

218 ultrasonic raw data were used to create B-mode images (depth $=30$ to $50 \mathrm{~mm}$, width $=55$

$219 \mathrm{~mm}$; in order to visualize the whole muscle thickness for each participant) by applying

220 conventional beamforming through Matlab software (Version, The Mathworks, Natick, MA).

221 The ultrasound probe was placed on the skin surface at $30 \%$ of the distance between the

222 popliteal fossa area and the centre of the lateral malleolus. A specific cast was used during

223 contractions to keep the probe in the same location throughout the measurements. Changes in

224 GM fascicle length (Fig. 2A) and pennation angle were assessed in every frame over $500 \mathrm{~ms}$

225 using the automatic tracking method proposed by Farris and Lichtwark (18) and low-pass

226 filtered $(50 \mathrm{~Hz})$ using a $3^{\text {rd }}$ order Butterworth filter. Fascicle shortening was calculated in

227 every frame over the same time window used to determine RTD (i.e., $200 \mathrm{~ms}$ ), over the whole

228 range of motion in the passive condition to build the fascicle force-length relationship.

229 Fascicle shortening velocity (Fig. 2C) was computed as the first-time derivative of fascicle

230 length. $\mathrm{V}_{\max }$ was calculated as the peak obtained during the no-load condition (25). Total

231 plantar flexion force was calculated from the torque divided by the Achilles tendon moment 
232 arm. Fascicle force was then calculated from the GM muscle force [i.e., 20.9\% of total plantar

233 flexion force (13)], divided by the cosine of the pennation angle.

234

235 Active force-length relationship. According to the method proposed by Hoffman et al. (28),

236 the parallel elastic component was considered parallel to the contractile element only. Thus,

237 the individual fascicle force-length curve was determined by fitting passive fascicle torque

238 data to the following equation (28):

$$
\text { Passive force }=A e^{k L_{f}}
$$

239 where $\mathrm{A}$ is constant, $\mathrm{k}$ is the stiffness of the curve and $\mathrm{L}_{\mathrm{f}}$ the fascicle length.

240 To build the fascicle total force-length relationship, the peak fascicle force and the 241 corresponding fascicle length when GM fascicle force was maximal were extracted for each 242 ankle angle condition $\left(30^{\circ}, 20^{\circ}, 10^{\circ}, 0^{\circ},-10^{\circ},-20^{\circ}\right.$ of plantar flexion; Fig. 2D). For each 243 point, the x-coordinate corresponded to the fascicle length measured when GM fascicle force 244 was maximal. The y-coordinate corresponded to the peak fascicle force minus the passive 245 force measured at the same fascicle length on the passive force-length curve (28). The active 246 force-length relationship was fitted using the previously suggested methods $(11,28)$. A 247 Levenberg-Marquardt algorithm was used to calculate five parameters (Origin 9.1, OriginLab 248 corporation, USA): the maximal force, the fascicle length at the maximal force (i.e., optimal 249 fascicle length, $\mathrm{L}_{0}$ ), the roundness, the skewness, and the width of the relationship. No 250 constraints were used, excepted when the fitted relationship resulted in non-physiological data 251 (see discussion section). The optimal fascicle length and maximal force were then used to 252 build the normalized force-length relationship for each individual and the whole sample of 253 participants. 
255 Force-velocity relationship. Neutral ankle position $\left(0^{\circ}\right)$ is the most-commonly used condition

256 to assess plantar flexion MVC torque and RTD, and resulted in the highest RTD values.

257 Therefore, peak fascicle force elicited during MVC performed at $0^{\circ}$ condition $\left(\mathrm{F}_{\max }\right)$ was used

258 as the maximal theoretical force for each individual (i.e., $\mathrm{F}_{0}$ of the force-velocity relationship;

259 Fig. 2E). This relationship was modelled using the hyperbolic equation (27):

$$
V=b *\left(F_{\max }-F\right) /(F+a)
$$

260 where $\mathrm{F}$ is force, $\mathrm{V}$ is velocity, and $\mathrm{a}$ and $\mathrm{b}$ are constants.

261 This model was fitted to experimental data that included $F_{\max }$ measured during RTD

262 evaluation performed at $0^{\circ}$ and $\mathrm{V}_{\max }$ assessed during no-load ballistic contractions (Fig. 2E).

263 The values of coefficients a (202.0) and b (17.0) were determined using the following 264 equation:

$$
\begin{aligned}
& a=k * F_{\text {max }} \\
& b=k * V_{\text {max }}
\end{aligned}
$$

265 where $\mathrm{k}$ is a constant.

266 The value of coefficient $\mathrm{k}(0.51)$ was determined from the mean force-velocity relationship

267 obtained in a previous study on participants with similar anthropometrical characteristics and

268 physical activity $(24,25)$. We determined the time point at which the mean fascicle force-

269 velocity data obtained during RTD testing crossed the lower limit of 95\% confidence interval

270 of the mean force-velocity relationship.

271

272 EMG. Surface EMG activity was recorded using a wireless remote unit (Zerowire, Aurion,

273 Italy), on GL, SOL and TA muscles. The skin was shaved, gently abraded and cleaned with a

274 solution of ether, acetone and alcohol to minimize inter-electrode impedance. The bipolar,

275 silver/silver chloride, surface disc electrodes (Blue Sensor N-00-S/25, Medicotest, France)

276 were placed with a center distance of $2 \mathrm{~cm}$. Electrodes were placed longitudinally with respect 
277 to the underlying muscle fibre arrangement and located according to the Surface EMG for the

278 Non-Invasive Assessment of Muscles recommendation's (SENIAM) (26). EMG signals were 279 pre-amplified (input impedance: $20 \mathrm{MX}$; common mode-rejection ratio: $90 \mathrm{~dB}$; gain: 1000;

280 bandwidth: 10-500 Hz), digitized and sampled at $2000 \mathrm{~Hz}$. All EMG signals were first band-

281 pass filtered (high pass: $10 \mathrm{~Hz}, 3^{\text {rd }}$ order Butterworth filter, low pass: $400 \mathrm{~Hz}, 3^{\text {rd }}$ order

282 Butterworth, filtered forward-backward filtering for zero phase shifting). EMG signals

283 obtained during RTD was analysed as the root mean square (RMS) with a 10 ms moving

284 rectangular window to produce a RMS envelope. During MVC, RMS EMG was calculated

285 using a 500-ms moving rectangular windows. The maximal RMS EMG amplitude measured

286 during maximal isometric contraction performed at the corresponding tested plantar flexion

287 angle was selected as the reference to normalize EMG data at the same testing angle. GL and

288 SOL EMG RMS were averaged over different time windows: between $0 \mathrm{~ms}$ and $50 \mathrm{ms,}$

289 between $50 \mathrm{~ms}$ and $100 \mathrm{~ms}$, between $100 \mathrm{~ms}$ and $200 \mathrm{~ms}$ and between $0 \mathrm{~ms}$ and $200 \mathrm{~ms}$.

\section{Statistical analysis}

292 All statistical analyses were performed with Statistica (StatSoft, Tulsa, Oklahoma, USA). All

293 data being normally distributed (Shapiro-Wilk's test), all results are expressed as means \pm s.d.

294 Statistical significance was set at $P<0.05$. The potential effects of ankle angle $\left(-20^{\circ},-10^{\circ}, 0^{\circ}\right.$, $29510^{\circ}, 20^{\circ}$ and $30^{\circ}$ ) on peak GM fascicle force, fascicle length corresponding to peak force,

296 fascicle length corresponding to the onset of RTD (in passive condition, before the onset of 297 the contraction), fascicle length changes over the first $200 \mathrm{~ms}$, peak fascicle shortening 298 velocity and time to peak shortening velocity were determined by one-way ANOVAs (angle 299 effect) with repeated measures. The effects of ankle angle $\left(-20^{\circ},-10^{\circ}, 0^{\circ}, 10^{\circ}, 20^{\circ}\right.$ and $\left.30^{\circ}\right)$ 300 and time period $(0-50,50-100$ and $100-200 \mathrm{~ms})$ on RTD were tested by a two-way ANOVA 301 (angle $\times$ time period) with repeated measures. Differences in muscle activation were tested for 
302

303

304

305

306

307

308

309

310

311

312

313

314

315

316

317

318

319

320

321

322

323

324

325

326

each muscle (GL and SOL) using two two-way ANOVAs (time $\times$ angle) with repeated measures. The $95 \%$ confidence interval was calculated for the force-velocity relationship (mean bias: $95 \%$, mean difference: \pm 1.96 s.d.). When the sphericity assumption in repeated measures ANOVAs was violated (Mauchly's test), a Geisser-Greenhouse correction was used. Post-hoc tests were performed by means of Newman-Keuls procedures for comparison between time points.

\section{RESULTS}

\section{Effect of joint angle on RTD}

Figure 3A shows changes in torque during RTD evaluation for all tested angles over time. The two-way ANOVA showed significant main effects of angle $(P<0.001)$, time period $(P<$ $0.001)$ and time period $\times$ angle interaction $(P<0.001)$ on RTD (Table 1). Post-hoc showed that no significant effect was found on $\operatorname{RTD}_{0-50}$ between $-10^{\circ}, 0^{\circ}$ and $10^{\circ}(P=0.29)$. These values were significantly higher than $\mathrm{RTD}_{0-50}$ measured at $-20^{\circ}(P<0.03)(17 \pm 6 \%)$, which was significantly higher than the values obtained at $20^{\circ}$ and $30^{\circ}(33 \pm 16 \%$ and $57 \pm 28 \%$, respectively; $P<0.005$ ). We found no significant differences in $\operatorname{RTD}_{50-100}$ between $-10^{\circ}, 0^{\circ}$ and $10^{\circ}(P=0.83)$, and these values were significantly higher than those obtained at $-20^{\circ}$ and $20^{\circ}(17 \pm 4 \%$ and $20 \pm 6 \%$, respectively; $P<0.04)$, which were significantly higher than $\mathrm{RTD}_{50-100}$ achieved at $30^{\circ}(28 \pm 13 \% ; P<0.001)$. $\mathrm{RTD}_{100-200}$ measured at $0^{\circ},-10^{\circ}$ and $-20^{\circ}$ were significantly higher than the values obtained at $10^{\circ}(11 \pm 4 \% ; P=0.02)$, which was significantly higher than the values obtained at $20^{\circ}$ and $30^{\circ}(12 \pm 3 \%$ and $33 \pm 3 \% ; P<0.02)$.

\section{Effect of joint angle on fascicle length and velocity changes during RTD evaluation}

At the two extreme ankle angle positions, GM fascicle operated from $3.6 \pm 0.7 \mathrm{~cm}$ to $2.8 \pm 0.6$ at $30^{\circ}$ and from $7.0 \pm 1.2 \mathrm{~cm}$ to $5.8 \pm 1.3 \mathrm{~cm}$ at $-20^{\circ}$ (Fig. 3). These fascicle length changes 
327 were significantly different between all conditions (angle effect; $P<0.05$ ), showing the

328 substantial effect of the ankle angle on this parameter. In all conditions, fascicle shortening 329 occurred mainly in the first $200 \mathrm{~ms}$, corresponding to $0.67 \pm 0.37 \mathrm{~cm}, 1.02 \pm 0.38 \mathrm{~cm}, 1.22 \pm$

$3300.49 \mathrm{~cm}, 1.21 \pm 0.48 \mathrm{~cm}, 1.06 \pm 0.40 \mathrm{~cm}$ and $0.85 \pm 0.33 \mathrm{~cm}$ for angles of $-20^{\circ},-10^{\circ}, 0^{\circ}, 10^{\circ}$,

$33120^{\circ}$ and $30^{\circ}$, respectively. Fascicle shortening was significantly lower at $-20^{\circ}$ than in other

332 conditions $(P<0.003)$. Peak fascicle shortening velocity showed a significant angle effect $(P$

$333<0.001)$, with a maximal value achieved at $0^{\circ}\left(10.8 \pm 3.8 \mathrm{~cm} \cdot \mathrm{s}^{-1}\right)$ and minimal at $20^{\circ}(6.7 \pm$

$3343.7 \mathrm{~cm} . \mathrm{s}^{-1}$; Table 1). Peak shortening velocity was significantly lower at $-20^{\circ}$ than at $-10^{\circ}, 0^{\circ}$, $33510^{\circ}, 20^{\circ}$ and $30^{\circ}(P<0.001)$.

336

\section{RTD performance in relation with force-length relationship}

338 In addition to the effect on muscle fascicle length changes, we observed a significant effect of

339 angle on peak fascicle force $(P<0.001)$ reached during RTD evaluation. Values ranged

340 between $180 \pm 49 \mathrm{~N}$ at $30^{\circ}$ and $568 \pm 177 \mathrm{~N}$ at $-20^{\circ}$ (Fig. 4). Post-hoc revealed that maximal

341 forces did not differ significantly between $-20^{\circ},-10^{\circ}(565 \pm 129 \mathrm{~N})$ and $0^{\circ}(520 \pm 114 \mathrm{~N} ; P=$

342 0.08; Fig. 4). Maximal fascicle forces produced at these angles were higher than values

343 obtained in plantar flexion positions at $10^{\circ}, 20^{\circ}$ and $30^{\circ}(P<0.001)$. The figure 4 allowed to

344 determine whether the average changes in fascicle length during RTD occurred over the

345 ascending limb, descending limb or the plateau of the force-length relationship. On average,

346 muscle fascicle operated over the ascending limb during RTD at $30^{\circ}$ and $20^{\circ}$, while it was

347 over the descending limb at $-20^{\circ}$. Changes in fascicle length during RTD performed at 10 and

$348-10^{\circ}$ were mainly comprised between the ascending limb and the plateau at $10^{\circ}$ and between

349 the descending limb and the plateau at $-10^{\circ}$. Finally, the fascicles operated over the plateau

350 when RTD was performed at $0^{\circ}$. 
351 The individual changes in length during RTD were analysed to further confirm these results

352 (Fig. 5). First, this individual analysis showed that the changes in fascicle length that occurred 353 during RTD at $30^{\circ}$ and $20^{\circ}$ corresponded to the ascending limb for all the participants.

354 Inversely, the changes in fascicle length during RTD performed at $-20^{\circ}$ corresponded to the 355 descending limb for all the participants excepted for 3/16 (i.e., participants \# 4, 11 and 16) for 356 which muscle fascicles operated over the plateau in this condition. Second, at $10^{\circ}$, fascicle 357 length changes occurred over the ascending limb for $9 / 16$ participants $(\# 1,2,3,4,5,10,11$, $35814,16)$, the plateau for $6 / 16$ participants $(\# 7,8,9,12,13,15)$, and the descending limb for 359 1/16 participant (\#6). In the same way, the changes in length during RTD at $-10^{\circ}$ 360 corresponded to the ascending limb for 1/16 participants (\#11), the plateau for $7 / 16$ 361 participants (\# 2, 3, 4, 5, 9, 10, 16) and the descending limb for 8/16 participants (\#1, 6, 7, 8,

$36212,13,14,15)$. Third, the changes in fascicle length during RTD at $0^{\circ}$ corresponded to the 363 ascending limb for $1 / 16$ participant (\#11), the plateau for $11 / 16$ participants $(\# 1,2,3,4,5,8$, $3649,10,12,14,16)$ and the descending limb for $4 / 16$ participants $(\# 6,7,13,15)$.

\section{RTD performance in relation with fascicle force-velocity relationship}

367 The $0^{\circ}$ condition elicited a fascicle shortening range centred over optimal GM fascicle length 368 values commonly reported in voluntary contractions (i.e., $\sim 5 \mathrm{~cm}$, Fig. 2D). The average force-

369 velocity relationship of GM is displayed in Figure 6. The theoretical maximal fascicle force 370 and maximal fascicle shortening velocity obtained from this relationship reached $521 \pm 115 \mathrm{~N}$ 371 and $33.3 \pm 8.8 \mathrm{~cm} \cdot \mathrm{s}^{-1}$, respectively. At $50 \mathrm{~ms}$ after the onset of RTD evaluation, the measured 372 fascicle force $(51 \pm 30 \mathrm{~N})$ was low compared to the theoretical maximal force the individuals 373 were able to produce at the corresponding fascicle-shortening velocity (278 $\pm 61 \mathrm{~N}$, Fig. 6).

374 Between 50 and $100 \mathrm{~ms}$, the force increased up to $177 \pm 73 \mathrm{~N}$ (i.e., $72.5 \%$ of the theoretical 375 maximum force at this corresponding specific shortening velocity) while the shortening 
376 velocity continued to increase and reached a plateau corresponding to $9.26 \pm 2.85 \mathrm{~cm} . \mathrm{s}^{-1}$ (i.e.,

$37728.2 \%$ of $\mathrm{V}_{\max }$ ). At $112 \mathrm{~ms}$, fascicle force reached $208 \pm 78 \mathrm{~N}$ (i.e., $85.6 \%$ of the theoretical

378 maximum force at this velocity) and was thereafter comprised within the $95 \%$ confidence

379 interval of the force-velocity relationship up to $F_{\max }$.

380

381 Muscle activity. GL mean muscle activity showed no significant effect of angle $(P=0.6)$ and

382 time $\times$ angle interaction $(P=0.2)$, with a significant effect of time $(P<0.001$; Fig. 3D, Table

383 1). Post-hoc showed that GL mean activity between 50 and $100 \mathrm{~ms}$ was significantly higher

384 than activity measured 0 and $50 \mathrm{~ms}$ and between 100 and $200 \mathrm{~ms}(P<0.001)$.

385 SOL mean muscle activity showed the significant effect of angle $(P<0.001)$, time $(P<$

$3860.001)$ and time $\times$ angle interaction $(P=0.001$, Table 1$)$. Post-hoc showed than SOL activity

387 was significantly higher at $-20^{\circ},-10^{\circ}$ and $0^{\circ}$ than at $20^{\circ}$ and $30^{\circ}(P<0.02)$. SOL mean

388 activity between 0 and $50 \mathrm{~ms}$ was significantly lower than between 50 and $100 \mathrm{~ms}$ or between

389100 and $200 \mathrm{~ms}(P<0.001)$.

390

391 DISCUSSION

392 The present study aimed to determine the influence of joint angle on the plantar flexor

393 RTD and associated fascicle dynamics measured during an explosive isometric contraction. In

394 line with our hypothesis, the results revealed a significant shortening of GM fascicles during

395 explosive isometric contractions, which was significantly influenced by joint angle. RTD

396 measured over a $200-\mathrm{ms}$ period reached higher values at $10^{\circ}, 0^{\circ}$ and $10^{\circ}$ than in dorsiflexed (-

$\left.39720^{\circ}\right)$ and plantar flexed $\left(20^{\circ}\right.$ and $\left.30^{\circ}\right)$ positions. This could mainly originate from the fact that

398 GM fascicles operate over the plateau of the force-length relationship in these neutral

399 conditions (i.e., centred on optimal fascicle length). At $0^{\circ}$, fascicle-shortening velocity

400 reached $\sim 28.2 \%$ of $\mathrm{V}_{\max }$ at $89 \mathrm{~ms}$ from $\mathrm{RTD}$ onset. This finding reflects that the substantial 
401 fascicle shortening that occurs in the isometric condition causes a decrease in maximal

402 fascicle force-generating capacity, according to the force-velocity relationship.

403 Plantar flexor RTD values $\left(346 \pm 38 \mathrm{~N} \cdot \mathrm{m} . \mathrm{s}^{-1}\right.$ and $417 \pm 137 \mathrm{~N} \cdot \mathrm{m} . \mathrm{s}^{-1}$ for RTD $0-50$ and

$404 \mathrm{RTD}_{0-200}$, respectively) were comprised within the ranges of RTD measures obtained during

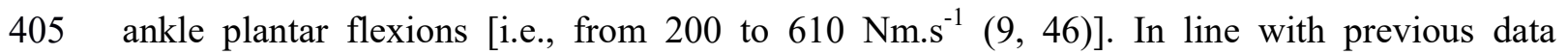

406 obtained on knee extensor muscles (34), our results show that the impact of ankle joint angle

407 on RTD follows an inverted 'U' relationship at any specific time point. To our knowledge, this

408 effect has never been reported for plantar flexors, while our results corroborate previous

409 studies focused on knee extensor muscles $(2,14)$. In the latter study, a change in ability to

410 produce force rapidly was associated with changes in muscle activation. These previous

411 findings are in accordance with the concomitant increase in EMG activity of SOL [i.e. main

412 contributor to planter flexor force (13)], and RFD observed in the present study at $-20^{\circ},-10^{\circ}$

413 and $0^{\circ}$ than $20^{\circ}$ and $30^{\circ}$. However, our results showed no significant effect of ankle angle on

414 average GL EMG activity across different time windows (Table 1). It is important to note that

415 GM and antagonist activity were not measured, which precludes to strongly conclude on the 416 influence of joint angle on muscle activation during RTD evaluation.

417 We observed a significant fascicle shortening during explosive isometric contractions, 418 regardless of ankle position (Fig. 3 and 4). Such a non-isometric behaviour of the fascicle 419 provides an additional evidence of the decoupling between muscle fibres (which shorten) and 420 tendon (which stretches) observed during various motor tasks [i.e., walking, running, 421 jumping, single-joint dynamic contractions $(21,29)]$. The significant effect of joint angle on 422 RTD can be interpreted with respect to the muscle fascicle shortening potential and the 423 associated muscle force-generating capacity, which depend on the initial muscle-tendon 424 length configuration $(7,28,38)$. 
The mean operating fascicle length during $\mathrm{RTD}_{0-200}$ performed at $0^{\circ}$ was comprised

426 between $5.87 \pm 0.84 \mathrm{~cm}$ and $4.64 \pm 0.99 \mathrm{~cm}$, which strongly corresponds to the optimal length 427 condition to produce force for GM muscle [Fig. 4; (28)]. Although a substantial variability 428 was found between individuals, this finding was confirmed by individual analyses (Fig. 5). At $30^{\circ}$ and $20^{\circ}$, muscle fascicles shortened over the ascending limb of the active force-length relationship, thereby limiting force and RTD. The resulting RTD in these conditions was significantly lower compared to the values elicited in neutral conditions where fascicles operated over the plateau (Fig. 4; Table 1). In the same way, at $-20^{\circ}$ (dorsiflexed ankle 433 position), RTD values were lower than those obtained at $0^{\circ}$ (Table 1 ). In this condition, GM fascicle mainly operated over the descending limb of the force-length relationship. Therefore, due to a decrease in the maximal force ability over the fascicle operating length, our results strongly support that the force-length properties can contribute to limit the amount of RTD achieved at $30^{\circ}, 20^{\circ}$ and $-20^{\circ}$. Nevertheless, this mechanism should be considered together with the potential impact of ankle angle on neural activation $(17,41)$. For intermediate angles $\left(10^{\circ}\right.$ and $\left.-10^{\circ}\right)$, the fascicle shortening during RTD was between the ascending, descending limb and the plateau. Therefore, the influence of the force-length relationship is more 441 mitigated for these conditions. Interestingly, while a trend was observed, RTD did not 442 significantly differ between $10^{\circ}, 0^{\circ}$ and $-10^{\circ}$. As a whole, these results demonstrated that 443 using a neutral ankle position around $0^{\circ}$ for RTD evaluation ensures a maximal force444 generating capacity in respect to the force-length relationship, and a minimal influence of the 445 force-length properties on the amount of produced muscle force. This finding is important 446 because it was the condition to further analyse the $0^{\circ}$ condition by investigating the force 447 development in light of the force-velocity properties.

448 Our results enable the identification of different phases of RTD performed in this $0^{\circ}$ 449 neutral condition. Firstly, from 0 to $50 \mathrm{~ms}$, mean EMG activity (Table 1) and fascicle force 
generated at the associated fascicle velocity was divergent from the maximal EMG activity

451 and the maximal force-velocity capacities of individuals. Therefore, in this phase, RTD may

452 be mainly related to the activation dynamics. Indeed, Del Vecchio et al. (16) showed that the

453 individual ability to produce force rapidly in this early phase of RTD is highly dependent on

454 motor unit recruitment and discharge rate. Secondly, from 50 to $100 \mathrm{~ms}$, the mean fascicle

455 force generated at the associated velocity progressively approached the force-velocity

456 relationship (Fig. 6). During this phase, EMG activity was significantly higher than in the

457 other time windows. Thus, in this phase, explosive strength still depends on activation and

458 progressively on the force-velocity properties. Thirdly, after $\sim 100 \mathrm{~ms}$, the mean fascicle force

459 generated at the associated fascicle velocity measured during RTD matched with the maximal

460 force-velocity properties (Fig. 6).

461 These results confirm previous results obtained on knee extensor muscles (14). In the

462 latter study, the response to an evoked octet was reported as the primary determinant of force

463 development from 50 to $100 \mathrm{~ms}$, suggesting that contractile properties of the muscle-tendon

464 unit may influence the force increase from $50 \mathrm{~ms}$ after the onset of contraction. Moreover, in

465 our study, fascicle force in the later part of RTD (after $200 \mathrm{~ms}$ ) is strongly related to the

466 maximal isometric force-generating capacity as demonstrated by the force-velocity values

467 measured close to $F_{\max }$. This result supports previous reports of an increasing influence of

468 maximal voluntary isometric torque on RTD measured over this later period of contraction (4,

469 19). The later putative intervention of contractile properties in plantar flexors may reflect the

470 influence of their pennate architecture as contractile forces are less directly transmitted to the

471 tendon than in less pennated muscles [e.g. knee extensors (48)]. Inversely, the gearing effect

472 allowed by fascicle pennation has been suggested to limit fascicle shortening velocity for

473 reaching a given muscle-tendon unit shortening velocity, which could increase RTD $(6,10)$.

474 How these two processes are involved in force rise remain to be elucidated. 
The impact of fascicle dynamics on RTD could be influenced by the stiffness of the

476 elastic tissues $(19,36,37,41)$. Waugh et al. (53) showed that Achilles tendon stiffness could

477 account for up to $35 \%$ of the variability in RTD normalized to its peak value, while Kubo (31)

478 suggested that the link between changes in tendon properties and RTD may be divergent.

479 Mayfield, et al. (41, 42) showed a modest decrease in fascicle shortening velocity with

480 increasing the effective stiffness (manipulated by applying a rapid rotation of the foot at the

481 onset of contraction) during electrically-evoked RTD, thereby increasing force-generating

482 capacity. During voluntary contractions, the present protocol placed the elastic tissues in a

483 configuration where their passive stiffness increased when the ankle was in dorsiflexed

484 angles. The present study confirms that this rise in tendon stiffness in dorsiflexed positions

485 reduces fascicle shortening velocity (Table 1). However, although the decrease in fascicle

486 velocity is theoretically beneficial for producing high levels of force rapidly, mean RTD was

487 significantly lower at $-20^{\circ}$ over each time window compared to $0^{\circ}$. This finding suggests that

488 the impairment of the force-generating capacity during RTD in dorsiflexed ankle

489 configuration is mainly related to the fact that fascicles are forced to operate over the

490 descending limb of the force-length relationship. This result clearly shows the interplay

491 between tendon stiffness and fascicle mechanics that remain very difficult to dissociate in vivo

492 and may in turn substantially contribute to the observed variability between individuals.

493 Future research is required to find the best compromise between the mechanical properties of

494 both tendinous and contractile tissues, and thereby optimize fascicle dynamics for RTD 495 performance.

496 The fits applied to the active voluntary force-length relationships were done in the 497 same way than in previous published papers $(11,28)$. However, it should be kept in mind that 498 it requires the calculation of five parameters. For such fits, we cannot fully ascertain that the 499 real solution was found by optimization due to possible local minima. Thus, the fit should be 
rather considered as an estimation about the theoretical force-length relationship. This should

501 not be considered as a main issue given that the parameters extracted from the fits were not 502 used in the present paper, excepted $\mathrm{F}_{0}$ and $\mathrm{L}_{0}$ for the average normalized force-length 503 relationship (Fig. 4B). In addition, for three participants (\#11, 13 and 16, Fig. 5), the $\mathrm{L}_{0}$ was 504 extrapolated in regards to the measured data points. Thus, the normalized force-length 505 relationship should be considered with caution. The force-velocity relationship was estimated 506 from Hill's model that was fitted on the basis of measured values of maximal force and 507 maximal shortening velocity. First, we assume that the fascicle velocity reached during no508 load ballistic plantar flexions is representative of the theoretical maximal velocity value (5). 509 Indeed, previous studies from our group have shown this method to be effective in assessing 510 the active $\mathrm{V}_{\max }$ that muscle fascicles can achieve in vivo $(7,23,25)$. Second, the curvature 511 coefficients were taken from the mean values of a previous study (25). Ideally, the fascicle 512 force-velocity curvature coefficient could be individualized from data collected under 513 different loading conditions (25). The inclusion of concentric contractions at various 514 velocities would have also permitted to consider the intricate influence of both length and 515 velocity changes on RTD at intermediate shortening velocities using a 3-D force-length516 velocity relationship $(50,52)$. However, in the present study, it was not possible to add the 517 conditions required for this procedure due to the increased of fatigue due to this protocol. 518 Nevertheless, compared to the study by Hauraix et al. (25), participants had similar (i) 519 anthropometrical characteristics, (ii) maximal velocity (i.e., $30.8 \mathrm{~cm} . \mathrm{s}^{-1}$ vs. $33.3 \pm 8.8 \mathrm{~cm} . \mathrm{s}^{-1}$ ) 520 and (iii) maximal force $(420 \mathrm{~N}$ vs. $520 \pm 115 \mathrm{~N})$. Therefore, we are confident that our 521 approach is sufficiently robust to interpret the force and fascicle shortening velocity obtained 522 during isometric RTD testing in light of the mean force-velocity relationship. 
The present study demonstrates that joint angle substantial influence the rate of torque

526 development, associated fascicle length changes and shortening velocity expressed during

527 explosive maximal isometric plantar flexions. Force-length properties mainly account for the

528 effect of ankle angle on RTD, which peaked around the neutral ankle positions where

529 fascicles operated over the plateau of the fascicle force-length relationship. After $\sim 100 \mathrm{~ms}$

530 from the onset of RTD, the fascicle force was very close to its maximal theoretical value

531 considering the associated shortening velocity (i.e., according to the force-velocity

532 relationship). While an initial phase is required to initiate the tendon stretch and maximally

533 activate the muscle, RTD is mainly influenced by muscle mechanics and the force-velocity

534 properties from $100 \mathrm{~ms}$ after RTD onset. This contribution of contractile properties to the

535 ability to generate force rapidly may also be modulated by the mechanical properties of elastic

536 tissues due to the inherent interplay between muscle and tendon in vivo. The present study

537 provides important information to better understand the determinants of human muscle

538 performance during explosive tasks. In the long term, it can be used to implement

539 individualized training programs and improve explosive strength. 
541 The authors are grateful to Aurélien Vauquelin and Clémence Damay (Eraclès-Technology)

542 for the conception and design of the mechatronic ergometer resulting from a valuable

543 collaboration, Simon Avrillon and Enzo Hollville for their contribution during pre-

544 experiments and the participants who took part in the study.

\section{GRANTS}

547 R. Hager received a sponsorship funding from Actech. The Laboratory Sport, Expertise and

548 Performance is a partner of the French network ReFORM, recognized as a Research Centre 549 for the Prevention of Injury and Illness and the Protection of Athletes by the International 550 Olympic Committee (IOC). As a member of the IOC Medical Research Network, ReFORM 551 has received funding from the IOC to establish long-term research programmes on the 552 prevention of injuries and illnesses in sport for the protection of athlete health.

\section{DISCLOSURES}

555 No conflicts of interest, financial or otherwise, are declared by the authors.

556

557 AUTHOR CONTRIBUTIONS

558 R.H., A.N., S.D. and G.G. conception and design of research; R.H. and T.P. performed 559 experiments. R.H., T.P., A.N., S.D. and G.G. analysed data; R.H., T.P., A.N., S.D. and G.G. 560 interpreted results of experiments; R.H., A.N., S.D. and G.G. prepared figures; R.H. drafted 561 manuscript; R.H., A.N., S.D. and G.G. edited and revised manuscript; R.H., T.P., A.N., S.D. 562 and G.G. approved final version of manuscript. 
Table 1. Rate of torque development, peak fascicle velocity, and mean EMG activity in gastrocnemius lateralis and soleus muscles measured at different ankle angles.

\begin{tabular}{|c|c|c|c|c|c|c|}
\hline Ankle angle & $-20^{\circ}$ (a) & $-10^{\circ(b)}$ & $0^{\circ}(\mathrm{c})$ & $10^{\circ(\mathrm{d})}$ & $20^{\circ(e)}$ & $30^{\circ(f)}$ \\
\hline $\begin{array}{l}\text { RTD }\left(\mathbf{N m} \cdot \mathbf{s}^{-1}\right) \\
0-200 \mathrm{~ms} \\
0-50^{\mathrm{hi}} \mathrm{ms} \\
50-100^{\mathrm{g}} \mathrm{ms} \\
100-200^{\mathrm{g}} \mathrm{ms} \\
\end{array}$ & $\begin{array}{c}320 \pm 91^{\text {cet }} \\
141 \pm 61^{\text {bcdef }} \\
413 \pm 136^{\text {bcdf }} \\
361 \pm 128^{\text {ef }}\end{array}$ & $\begin{array}{c}354 \pm 117^{\text {et }} \\
208 \pm 127^{\text {aef }} \\
496 \pm 210^{\dagger} \\
357 \pm 128^{\text {ef }}\end{array}$ & $\begin{array}{c}389 \pm 94^{\text {aet }} \\
178 \pm 105^{\text {aef }} \\
549 \pm 178^{\text {aef }} \\
414 \pm 98^{\text {def }}\end{array}$ & $\begin{array}{c}329 \pm 94^{\text {et }} \\
203 \pm 113^{\text {aef }} \\
483 \pm 168^{\dagger} \\
317 \pm 81^{\text {cf }}\end{array}$ & $\begin{array}{c}265 \pm 66^{\mathrm{abcdt}} \\
106 \pm 53^{\mathrm{bdc}} \\
388 \pm 150^{\mathrm{cf}} \\
284 \pm 60^{\mathrm{abct}}\end{array}$ & $\begin{array}{c}194.5 \pm 53^{\text {abcde }} \\
81 \pm 45^{\text {bdc }} \\
280 \pm 129^{\text {abcde }} \\
210 \pm 59^{\text {abcde }}\end{array}$ \\
\hline Peak Fascicle velocity $\left(\mathrm{cm} . \mathrm{s}^{-1}\right)$ & $6.1 \pm 3.4^{\text {bcdef }}$ & $8.6 \pm 4.0^{\mathrm{a}}$ & $10.8 \pm 3.8^{\mathrm{a}}$ & $10.6 \pm 3.0^{\mathrm{a}}$ & $9.8 \pm 3.2^{\mathrm{a}}$ & $8.6+3.4^{\mathrm{a}}$ \\
\hline $\begin{array}{l}\text { Mean EMG GL (\% RMS max) } \\
0-200 \mathrm{~ms} \\
0-50^{\mathrm{h}} \mathrm{ms} \\
50-100^{\mathrm{gi}} \mathrm{ms} \\
100-200^{\mathrm{h}} \mathrm{ms}\end{array}$ & $\begin{array}{c}69.7 \pm 11.0 \\
67.2 \pm 27.9 \\
87.0 \pm 19.7 \\
62.5 \pm 22.3^{\mathrm{g}}\end{array}$ & $\begin{array}{c}64.6 \pm 24.6 \\
68.3 \pm 37 \\
78.6 \pm 35.1 \\
57.8 \pm 18.6^{9}\end{array}$ & $\begin{array}{c}62.3 \pm 18.4 \\
58.6 \pm 27.8 \\
72.9 \pm 23.2 \\
60.5 \pm 19.2^{g}\end{array}$ & $\begin{array}{c}65.7 \pm 21.0 \\
66.1 \pm 27.1 \\
75.5 \pm 24.4 \\
62.7 \pm 18.1^{9}\end{array}$ & $\begin{array}{l}62.2 \pm 18.7 \\
53.1 \pm 21.3 \\
69.7 \pm 24.0 \\
64.5 \pm 17.3 \\
\end{array}$ & $\begin{array}{l}72.0 \pm 17.1 \\
61.8 \pm 25.0 \\
76.9 \pm 20.1 \\
76.3 \pm 16.6 \\
\end{array}$ \\
\hline $\begin{array}{l}\text { Mean EMG SOL (\% RMS max) } \\
0-200 \mathrm{~ms} \\
0-50^{\mathrm{hi}} \mathrm{ms} \\
50-100^{\mathrm{g}} \mathrm{ms} \\
100-200^{\mathrm{g}} \mathrm{ms}\end{array}$ & $\begin{array}{l}57.4 \pm 23.6 \\
21.3 \pm 12.5 \\
71.2 \pm 33.5 \\
65.5 \pm 22.3\end{array}$ & $\begin{array}{c}51.7 \pm 27.1 \\
16.9 \pm 7.8 \\
78.6 \pm 50.1 \\
59.2 \pm 28.4\end{array}$ & $\begin{array}{c}50.7 \pm 23.6 \\
14.9 \pm 8.2 \\
62.0 \pm 32.1 \\
63.2 \pm 31.4\end{array}$ & $\begin{array}{c}43.4 \pm 19.0 \\
13.3 \pm 7.4 \\
52.9 \pm 30.1 \\
53.9 \pm 21.9\end{array}$ & $\begin{array}{c}36.8 \pm 14.9 \\
12.2 \pm 6.8 \\
41.0 \pm 19.5 \\
47.0 \pm 18.9\end{array}$ & $\begin{array}{c}37.8 \pm 18.8 \\
14.4 \pm 7.8 \\
40.5 \pm 24.5 \\
48.2 \pm 23.9\end{array}$ \\
\hline
\end{tabular}

Values are mean $\pm \operatorname{SD}(n=16)$.

$568{ }^{\mathrm{a}}, \mathrm{b},{ }^{\mathrm{c}},{ }^{\mathrm{d}},{ }^{\mathrm{e}}$ and ${ }^{\mathrm{f}}$ : significantly different than $-20^{\circ},-10^{\circ}, 0^{\circ}, 10^{\circ}, 20^{\circ}$, and $30^{\circ}$, respectively $[P<0.05$; two-way ANOVA, main effect: ankle angle $(-$ $\left.\left.56920^{\circ},-10^{\circ}, 0^{\circ}, 10^{\circ}, 20^{\circ}, 30^{\circ}\right)\right]$.

$570 \mathrm{~g},{ }^{\mathrm{h}}$ and ${ }^{\mathrm{i}}$ : significantly different than $\mathrm{RTD}_{0-50}, \mathrm{RTD}_{50-100}$ and $\mathrm{RTD}_{100-200}$, respectively $[P<0.05$; one-way ANOVA, main effects: ankle angle $(-$ $\left.57120^{\circ},-10^{\circ}, 0^{\circ}, 10^{\circ}, 20^{\circ}, 30^{\circ}\right) \times$ time period $\left.(0-50,50-100,100-200 \mathrm{~ms})\right]$.

572 MVC: maximal voluntary contraction; RMS: root mean square. 
Figure 1. Individual patterns of collected signals during RTD testing. Plantar flexor torque was recorded by a mechatronic ergometer triggered by a high-frame rate ultrasound scanner. Fascicle length and pennation angle were measured on ultrasound images processed using automatic tracking software. Fascicle length was differentiated derived to obtain fascicle velocity. Electromyographic (EMG) activity of gastrocnemius lateralis and soleus were recorded in time with ultrasound images and mechanical signals. The time corresponding to the onset of torque development (first arrow) was manually determined using the method proposed by (54).

Figure 2. Methodological approach used to obtain individual force-length and force velocity relationship. Force-length at MVC peak torque (D): Gastrocnemius medialis fascicle length (A) was recorded during RTD at different conditions $(-20,-10,0,10,20$ and $30^{\circ}$ ) using ultrasound. Fascicle force (B) was calculated from torque recordings, moment arm and pennation angle. Force-length at MVC peak torque (D) was built from the fascicle length corresponding at peak fascicle force (black circle for peak at $0^{\circ}, \mathrm{A}$ ) and associated fascicle force (green circle for peak at $0^{\circ}, \mathrm{B}$ ) minus the passive force produced at fascicle length corresponding to peak fascicle force (31). The range of fascicle shortening at $0^{\circ}$ plotted as a green trace (green-black circle).

594 Force-velocity relationship (E): Fascicle velocity (C) was calculated from fascicle length derivative. For the sake of clarity, only fascicle velocity at $0^{\circ}$ during RTD (green line) and during ballistic condition (dashed line) are presented here. From peak fascicle velocity (red circle, C) and force values (green circle, B), the individual force-velocity relationship was build (black trace in E). The curvature coefficient of the slope was defined using previous mean data collected by our group on a similar sample of participants (27). Fascicle shortening velocity during RTD was plotted as a rainbow trace, with the colour scale illustrating time from $0 \mathrm{~ms}$ (red) to $600 \mathrm{~ms}$ (purple).

603

Figure 3. Mean ( $n=16$ ) Torque (A), gastrocnemius medialis fascicle length (B), fascicle 604 torque was presented without the effect of passive tension.

605 Figure 4. Raw (A) and normalized (B) mean active force-length relationship obtained 606 during maximal contractions performed at $-20^{\circ},-10^{\circ}, 0^{\circ}, 10^{\circ}, 20^{\circ}$ and $30^{\circ}$ of ankle angle assuming the model B from Hoffman et al. [(29); $\mathrm{n}=16)$ ]. The force-length relationship was normalized $(\mathrm{B})$ using the maximal force $\left(\mathrm{F}_{0}\right)$ and the optimal fascicle length $\left(\mathrm{L}_{0}\right)$ obtained using individual fits. Colour traces represents the time-course of force and fascicle length changes that occurred during the evaluation of rate of torque development (RTD; i.e., from 0 $\mathrm{N}$ force to maximal values on the force-length relationship). The three black circles represent the values achieved at 50,100 and $200 \mathrm{~ms}$ during RTD. Fascicle forces values obtained at -

$61320^{\circ},-10^{\circ}$ and $0^{\circ}$ were significantly higher than values obtained at $10^{\circ}, 20^{\circ}$ and $30^{\circ}[P<$

6140.001 ; one-way ANOVA, main effect: ankle angle $\left(-20^{\circ},-10^{\circ}, 0^{\circ}, 10^{\circ}, 20^{\circ}\right.$ and $\left.\left.30^{\circ}\right)\right]$.

615 Figure 5. Individual active force-length relationship obtained during maximal contractions 616 performed at $-20^{\circ},-10^{\circ}, 0^{\circ}, 10^{\circ}, 20^{\circ}$ and $30^{\circ}$ of ankle angle assuming the model $\mathrm{B}$ from 617 Hoffman et al. 2012 for the 16 participants (P). 
618 Figure 6. Force-velocity relationship (black line) with associated lower $95 \%$ confidence 619 interval. The curvature coefficient of the slope was defined using previous mean data 620 collected by our group on a similar sample of participants $(n=16)(27)$. Fascicle force and 621 shortening velocity measured at $0^{\circ}$ of ankle angle during RTD was plotted as a rainbow trace, 622 with the color scale illustrating time from $0 \mathrm{~ms}$ (red) to $600 \mathrm{~ms}$ (purple). The three black 623 marks represents the mean fascicle length at 50, 100 and $200 \mathrm{~ms}$ from the onset of RTD 624 testing. 
626 1. Aagaard P, Simonsen EB, Andersen JL, Magnusson P, and Dyhre-Poulsen P.

627 Increased rate of force development and neural drive of human skeletal muscle following 628 resistance training. J Appl Physiol 93: 1318-1326, 2002.

629 2. Alexander RM, and Bennet-Clark HC. Storage of elastic strain energy in muscle

630 and other tissues. Nature 265: 114-117, 1977.

631 3. An KN, Takahashi K, Harrigan TP, and Chao EY. Determination of muscle

632 orientations and moment arms. J Biomech Eng 106: 280-282, 1984.

633 4. Andersen LL, and Aagaard P. Influence of maximal muscle strength and intrinsic

634 muscle contractile properties on contractile rate of force development. Eur J Appl Physiol 96:

635 46-52, 2006.

636 5. Andersen LL, Andersen JL, Zebis MK, and Aagaard P. Early and late rate of force

637 development: differential adaptive responses to resistance training? Scand J Med Sci Sports

638 20: e162-169, 2010.

639 6. Azizi E, and Deslauriers AR. Regional heterogeneity in muscle fiber strain: the role 640 of fiber architecture. Front Physiol 5: 303, 2014.

641 7. Beaumatin N, Hauraix H, Nordez A, Hager R, Rabita G, Guilhem G, and Dorel

642 S. Maximal shortening velocity during plantar flexion: Effects of pre-activity and initial 643 stretching state. Scand J Med Sci Sports 28: 1361-1370, 2018.

6448 8. Behan FP, Pain MTG, and Folland JP. Explosive voluntary torque is related to 645 whole-body response to unexpected perturbations. J Biomech 81: 86-92, 2018.

6469 9. Behm DG, Whittle J, Button D, and Power K. Intermuscle differences in activation.

647 Muscle Nerve 25: 236-243, 2002.

648 10. Brainerd EL, and Azizi E. Muscle fiber angle, segment bulging and architectural 649 gear ratio in segmented musculature. J Exp Biol 208: 3249-3261, 2005.

650 11. Brennan SF, Cresswell AG, Farris DJ, and Lichtwark GA. The effect of muscle-

651 tendon unit vs. fascicle analyses on vastus lateralis force-generating capacity during constant

652 power output cycling with variable cadence. Journal of applied physiology (Bethesda, Md :

653 1985) 124: 993-1002, 2018.

654 12. Cronin NJ, and Lichtwark G. The use of ultrasound to study muscle-tendon function in human posture and locomotion. Gait Posture 37: 305-312, 2013. 13. Crouzier M, Lacourpaille L, Nordez A, Tucker K, and Hug F. Neuromechanical coupling within the human triceps surae and its consequence on individual force-sharing strategies. J Exp Biol 221: 2018.

14. de Ruiter CJ, Kooistra RD, Paalman MI, and de Haan A. Initial phase of maximal voluntary and electrically stimulated knee extension torque development at different knee angles. J Appl Physiol 97: 1693-1701, 2004.

15. de Ruiter CJ, Vermeulen G, Toussaint HM, and de Haan A. Isometric kneeextensor torque development and jump height in volleyball players. Med Sci Sports Exerc 39: 1336-1346, 2007.

665 16. Del Vecchio A, Negro F, Holobar A, Casolo A, Folland JP, Felici F, and Farina D.

666 You are as fast as your motor neurons: speed of recruitment and maximal discharge of motor

667 neurons determine the maximal rate of force development in humans. J Physiol 597: 2445-

$6682456,2019$.

669 17. Duchateau J, and Enoka RM. Human motor unit recordings: Origins and insight into 670 the integrated motor system. Brain Res 2011.

671 18. Farris DJ, and Lichtwark GA. UltraTrack: Software for semi-automated tracking of 
674 19. Folland JP, Buckthorpe MW, and Hannah R. Human capacity for explosive force 675 production: neural and contractile determinants. Scand J Med Sci Sports 24: 894-906, 2014.

676 20. Fukunaga T, Kawakami Y, Kubo K, and Kanehisa H. Muscle and tendon

677 interaction during human movements. Exerc Sport Sci Rev 30: 106-110, 2002.

678 21. Fukunaga T, Kawakami Y, Kuno S, Funato K, and Fukashiro S. Muscle

679 architecture and function in humans. J Biomech 30: 457-463, 1997.

680 22. Gerstner GR, Giuliani HK, Mota JA, and Ryan ED. Age-related reductions in

681 muscle quality influence the relative differences in strength and power. Exp Gerontol 99: $27-$

$68234,2017$.

683 23. Hager R, Dorel S, Nordez A, Rabita G, Couturier A, Hauraix H, Duchateau J,

684 and Guilhem $\mathbf{G}$. The slack test does not assess maximal shortening velocity of muscle

685 fascicles in humans. J Exp Biol 221: 2018.

686 24. Hauraix H, Nordez A, and Dorel S. Shortening behavior of the different components

687 of muscle-tendon unit during isokinetic plantar flexions. J Appl Physiol 115: 1015-1024,

6882013.

689 25. Hauraix H, Nordez A, Guilhem G, Rabita G, and Dorel S. In vivo maximal

690 fascicle-shortening velocity during plantar flexion in humans. Journal of applied physiology

691 (Bethesda, Md : 1985) 119: 1262-1271, 2015.

692 26. Hermens HJ, Freriks B, Disselhorst-Klug C, and Rau G. Development of

693 recommendations for SEMG sensors and sensor placement procedures. J Electromyogr

694 Kinesiol 10: 361-374, 2000.

695 27. Hill AV. The heat of shortening and the dynamic constants of muscle. Proceedings of

696 the Royal Society of London Series B - Biological Sciences 126: 136-195, 1997.

697 28. Hoffman BW, Lichtwark GA, Carroll TJ, and Cresswell AG. A comparison of two

698 Hill-type skeletal muscle models on the construction of medial gastrocnemius length-tension

699 curves in humans in vivo. J Appl Physiol 113: 90-96, 2012.

$700 \quad 29 . \quad$ Ito M, Kawakami Y, Ichinose Y, Fukashiro S, and Fukunaga T. Nonisometric

701 behavior of fascicles during isometric contractions of a human muscle. J Appl Physiol 85:

702 1230-1235, 1998.

703 30. Kawakami Y, Ichinose Y, and Fukunaga T. Architectural and functional features of

704 human triceps surae muscles during contraction. J Appl Physiol 85: 398-404, 1998.

705 31. Kubo K, Kanehisa H, and Fukunaga T. Effects of resistance and stretching training

706 programmes on the viscoelastic properties of human tendon structures in vivo. J Physiol 538:

$707 \quad 219-226,2002$.

708 32. Kubo K, Kanehisa H, Kawakami Y, and Fukanaga T. Growth changes in the

709 elastic properties of human tendon structures. Int J Sports Med 22: 138-143, 2001.

$710 \quad 33 . \quad$ Lambertz D, Paiva MG, Marinho SM, Aragao RS, Barros KM, Manhaes-de-

711 Castro R, Khider N, and Canon F. A reproducibility study on musculotendinous stiffness

712 quantification, using a new transportable ankle ergometer device. J Biomech 41: 3270-3273,

7132008.

714 34. Lanza MB, Balshaw TG, and Folland JP. Explosive strength: effect of knee-joint

715 angle on functional, neural, and intrinsic contractile properties. Eur J Appl Physiol 119: 1735-

$716 \quad 1746,2019$.

$717 \quad 35 . \quad$ Lee SS, and Piazza SJ. Built for speed: musculoskeletal structure and sprinting

718 ability. J Exp Biol 212: 3700-3707, 2009.

719 36. Lichtwark GA, and Wilson AM. Is Achilles tendon compliance optimised for

720 maximum muscle efficiency during locomotion? J Biomech 40: 1768-1775, 2007.

721 37. Maffiuletti NA, Aagaard P, Blazevich AJ, Folland J, Tillin N, and Duchateau J.

722 Rate of force development: physiological and methodological considerations. Eur J Appl

723 Physiol 2016. 
38. Maganaris CN. Imaging-based estimates of moment arm length in intact human muscle-tendons. Eur J Appl Physiol 91: 130-139, 2004. 39. Maganaris $\mathbf{C N}$. A predictive model of moment-angle characteristics in human skeletal muscle: application and validation in muscles across the ankle joint. $J$ Theor Biol 230: 89-98, 2004.

40. Massey GJ, Balshaw TG, Maden-Wilkinson TM, Tillin NA, and Folland JP. The influence of patellar tendon and muscle-tendon unit stiffness on quadriceps explosive strength in man. Exp Physiol 2017.

41. Mayfield DL, Cresswell AG, and Lichtwark GA. Effects of series elastic compliance on muscle force summation and the rate of force rise. J Exp Biol 2016. 42. Mayfield DL, Lichtwark GA, Cronin NJ, Avela J, and Cresswell AG. Doublet potentiation in the triceps surae is limited by series compliance and dynamic fascicle behavior. Journal of applied physiology (Bethesda, Md : 1985) 119: 807-816, 2015.

43. Palmer TB, Hawkey MJ, Thiele RM, Conchola EC, Adams BM, Akehi K, Smith DB, and Thompson BJ. The influence of athletic status on maximal and rapid isometric torque characteristics and postural balance performance in Division I female soccer athletes and non-athlete controls. Clin Physiol Funct Imaging 35: 314-322, 2015.

44. Penailillo $\mathbf{L}$, Blazevich $\mathbf{A}$, Numazawa $\mathbf{H}$, and Nosaka $\mathbf{K}$. Rate of force development as a measure of muscle damage. Scand J Med Sci Sports 25: 417-427, 2015.

45. Reeves ND, and Narici MV. Behavior of human muscle fascicles during shortening and lengthening contractions in vivo. J Appl Physiol 95: 1090-1096, 2003.

46. Ricard MD, Ugrinowitsch C, Parcell AC, Hilton S, Rubley MD, Sawyer R, and Poole CR. Effects of rate of force development on EMG amplitude and frequency. Int $J$ Sports Med 26: 66-70, 2005.

47. Rousanoglou EN, Herzog W, and Boudolos KD. Moment-Angle Relations in the Initial Time of Contraction. Int J Sports Med 31: 651-655, 2010.

48. Spector SA, Gardiner PF, Zernicke RF, Roy RR, and Edgerton VR. Muscle architecture and force-velocity characteristics of cat soleus and medial gastrocnemius: implications for motor control. J Neurophysiol 44: 951-960, 1980.

49. Tillin NA, Jimenez-Reyes P, Pain MT, and Folland JP. Neuromuscular performance of explosive power athletes versus untrained individuals. Med Sci Sports Exerc 42: 781-790, 2010.

50. Tillin NA, Pain MT, and Folland JP. Contraction type influences the human ability to use the available torque capacity of skeletal muscle during explosive efforts. Proc Biol Sci 279: 2106-2115, 2012.

51. Tillin NA, Pain MT, and Folland JP. Identification of contraction onset during explosive contractions. Response to Thompson et al. "Consistency of rapid muscle force characteristics: Influence of muscle contraction onset detection methodology" [J Electromyogr Kinesiol 2012;22(6):893-900]. J Electromyogr Kinesiol 2013. 52. Tillin NA, Pain MTG, and Folland JP. Contraction speed and type influences rapid utilisation of available muscle force: neural and contractile mechanisms. J Exp Biol 221: 2018.

53. Waugh CM, Korff T, Fath F, and Blazevich AJ. Rapid force production in children and adults: mechanical and neural contributions. Med Sci Sports Exerc 45: 762-771, 2013. 


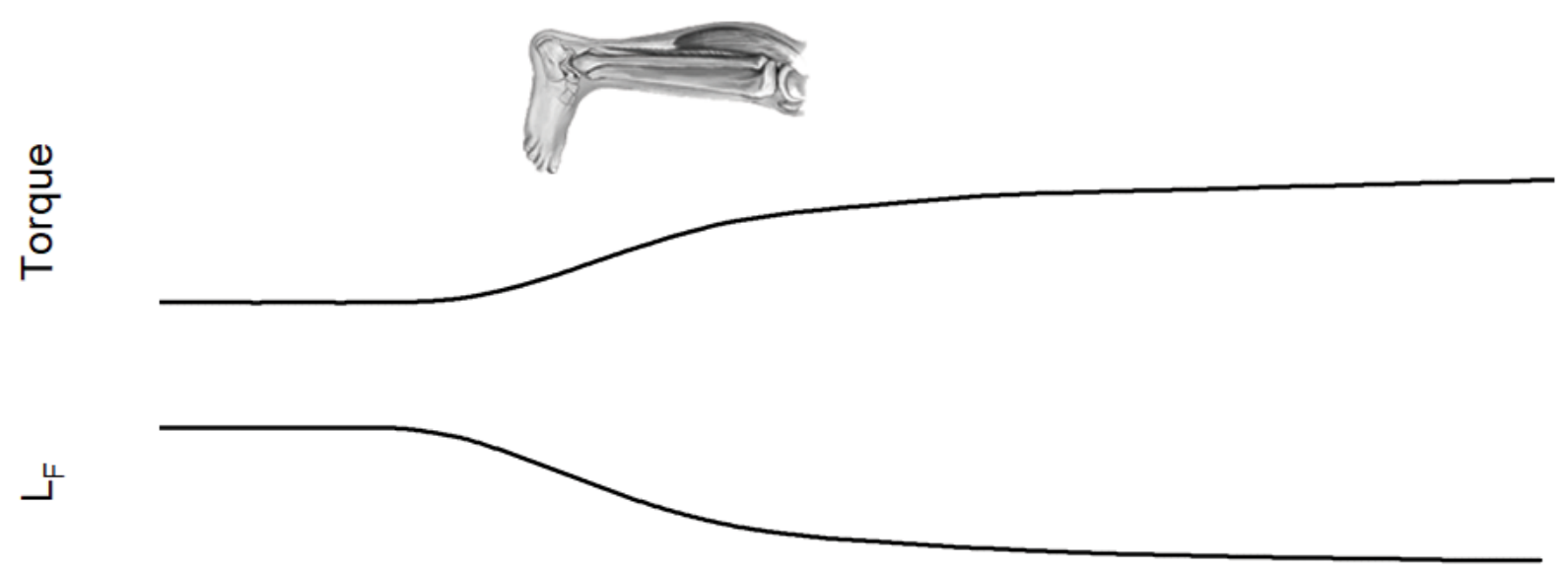

| $50 \mathrm{Nm}$

$\frac{\sqrt{2}}{2}$
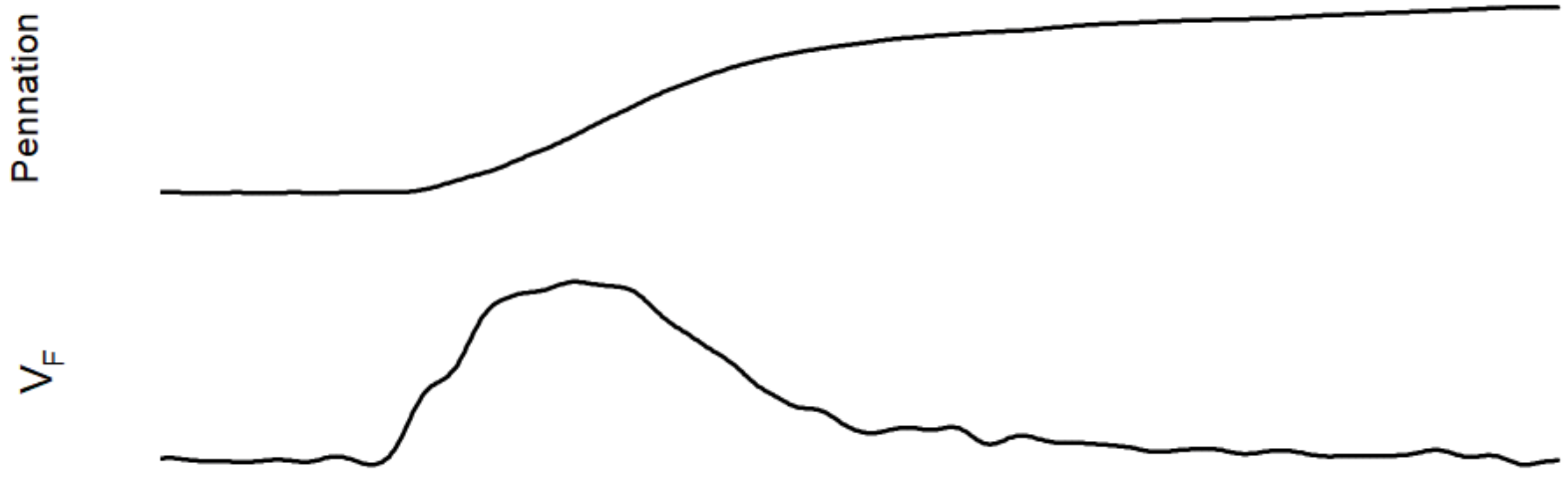

$\sum_{\square}^{10}$

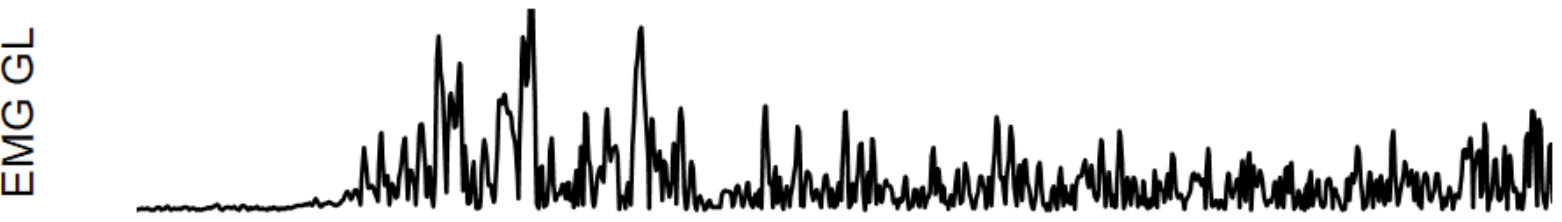

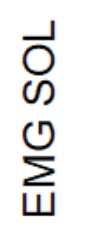
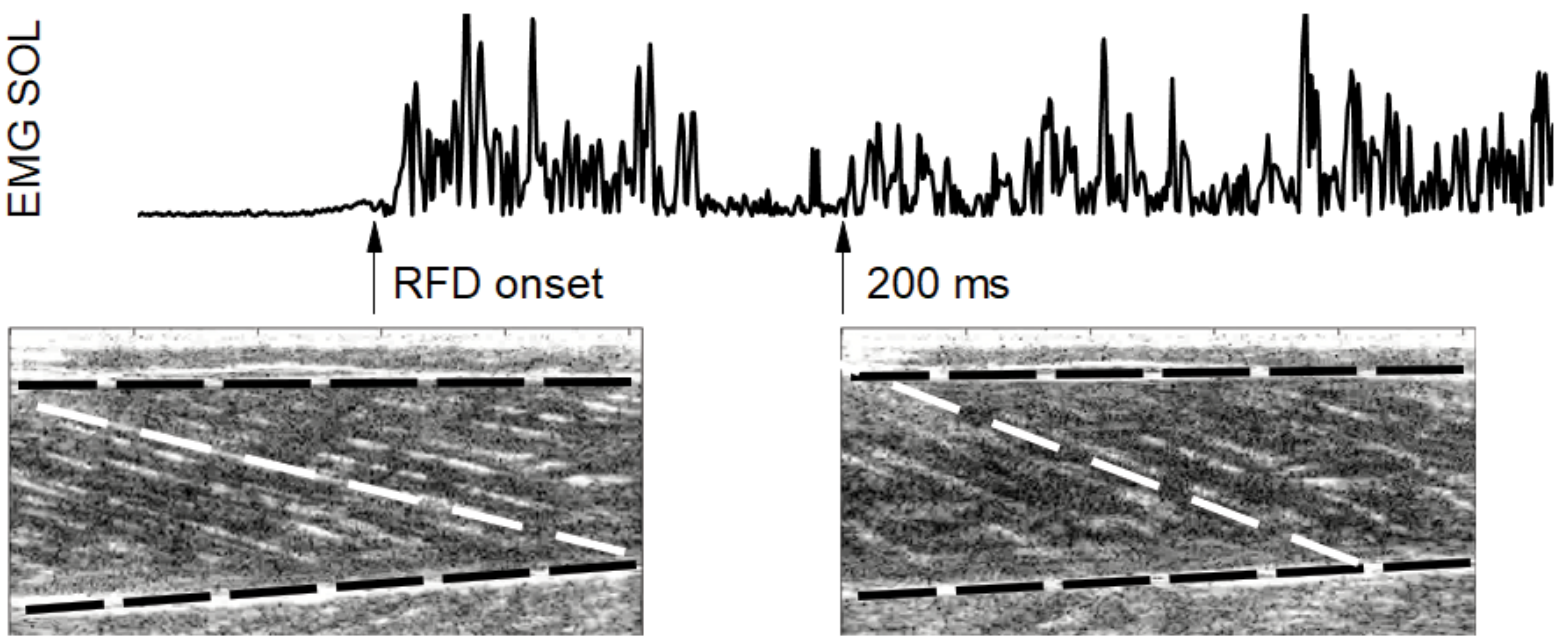

4 cm.s- 1

$14^{\circ}$

| 50\% EMG MAX 

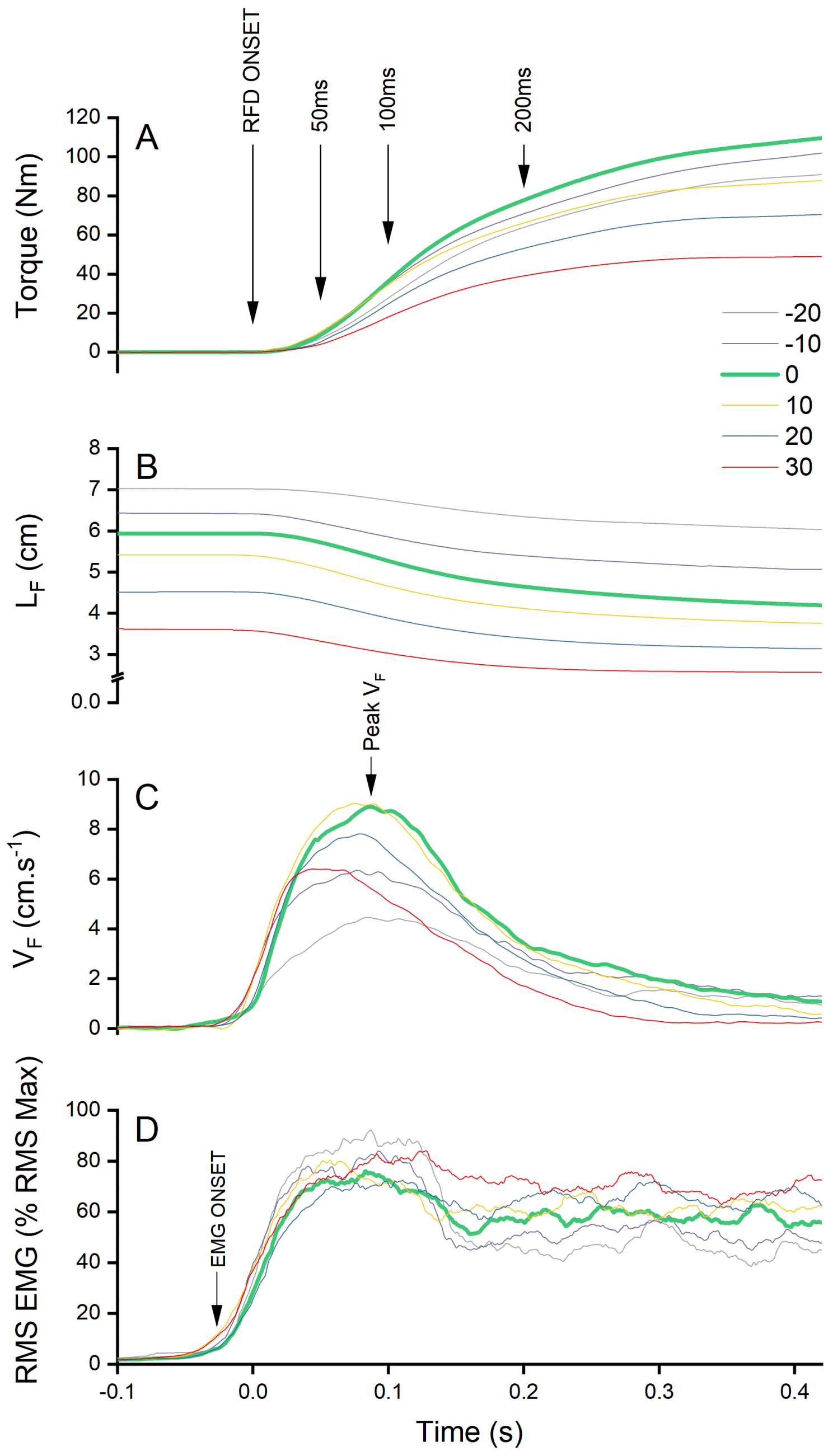

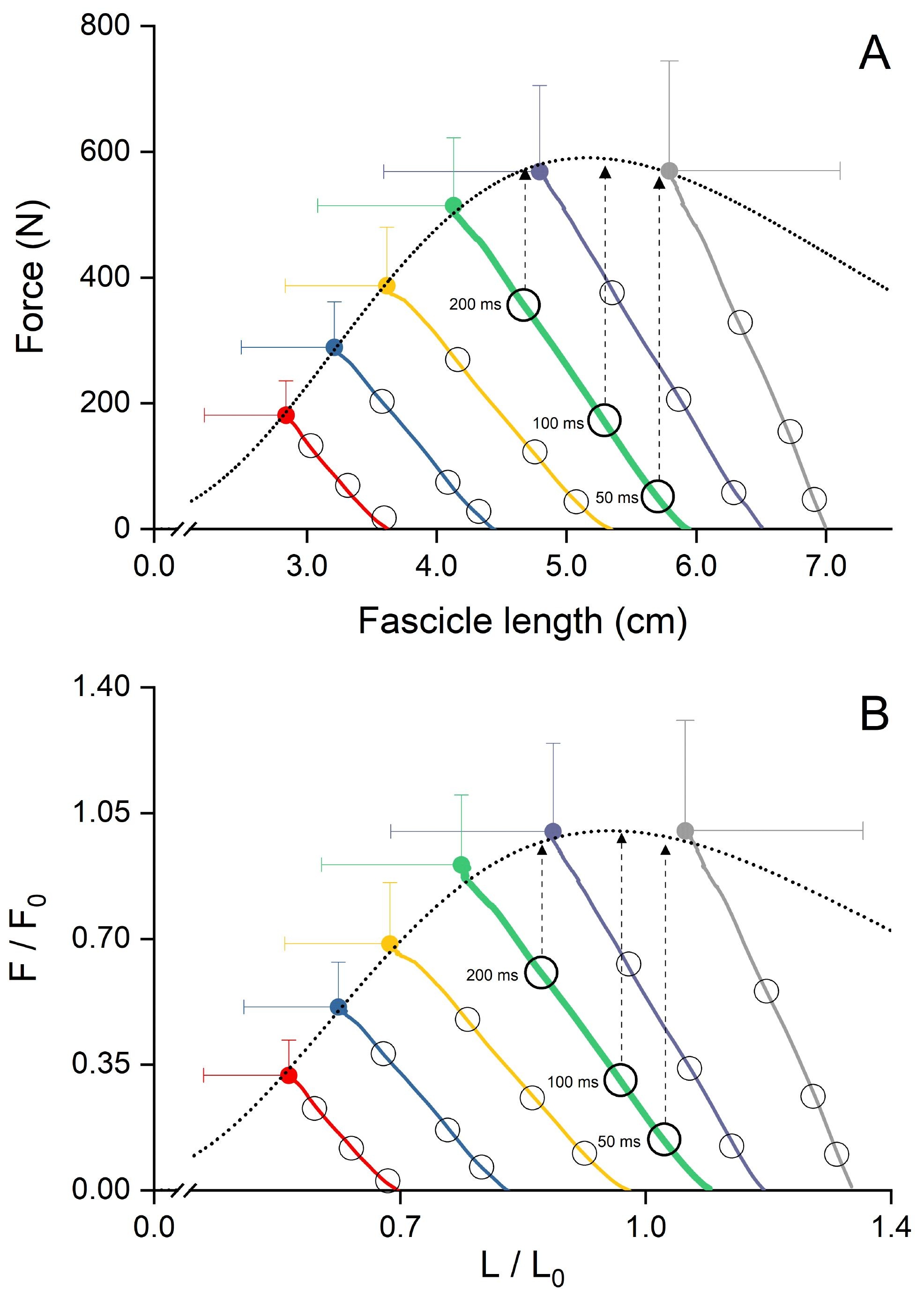

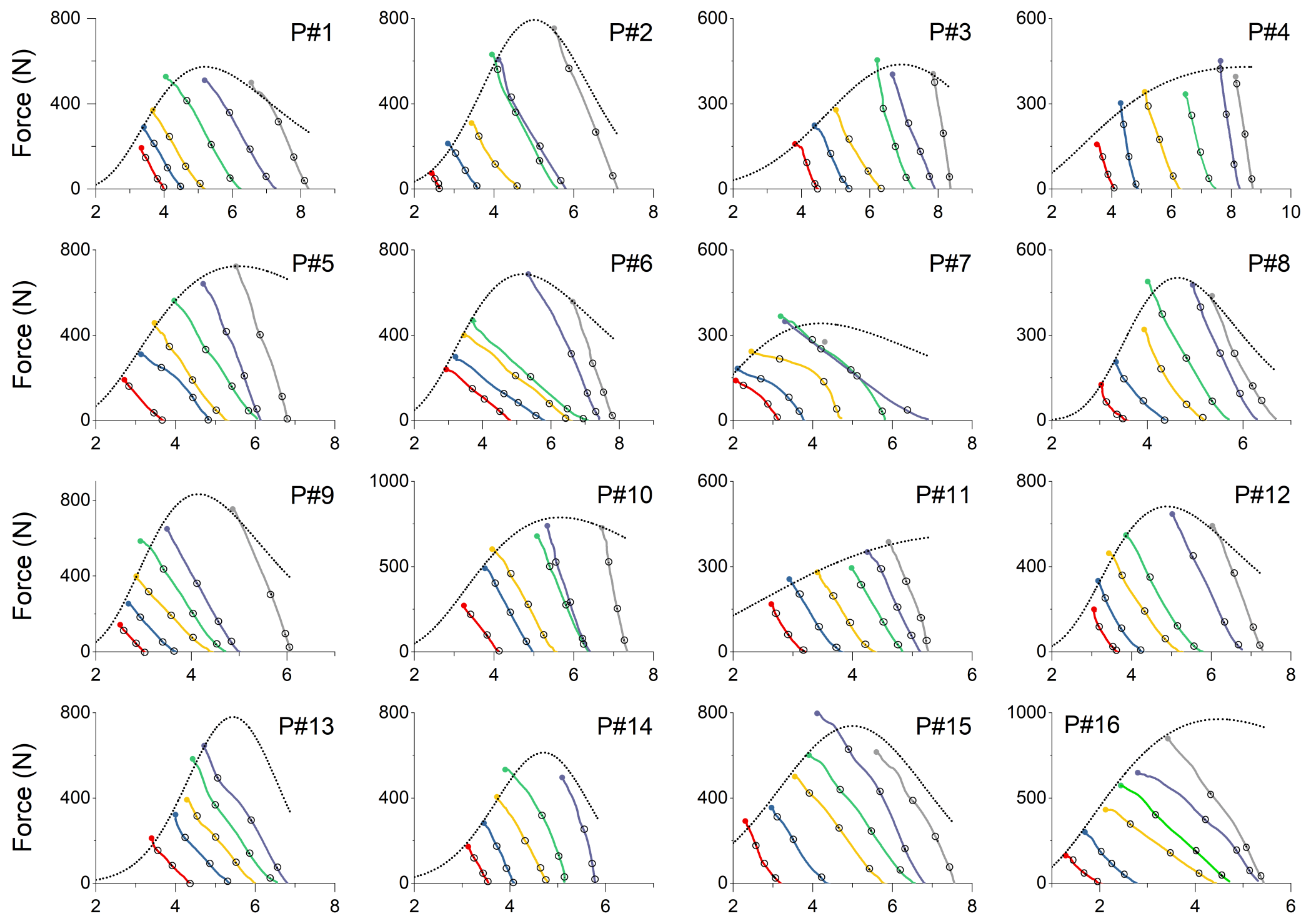

Fascicle length $(\mathrm{cm})$

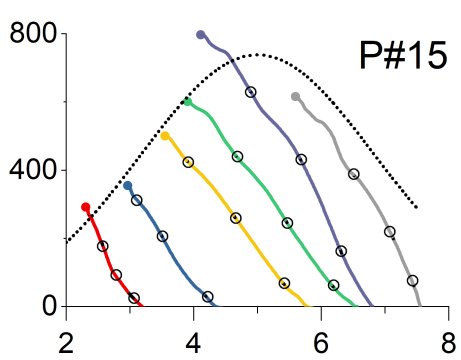

Fascicle length $(\mathrm{cm})$

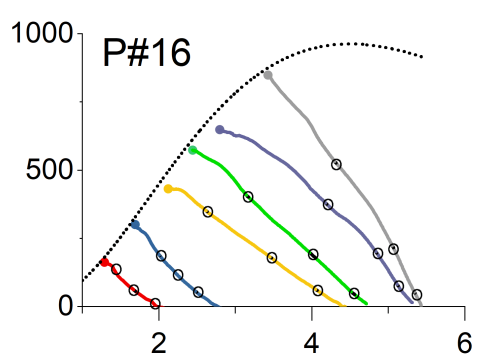

Fascicle length $(\mathrm{cm})$ $-20^{\circ} \cdot-10^{\circ} \cdot 0^{\circ} \cdot 10^{\circ} \cdot 20^{\circ} \cdot 30^{\circ}$ Force-length model 


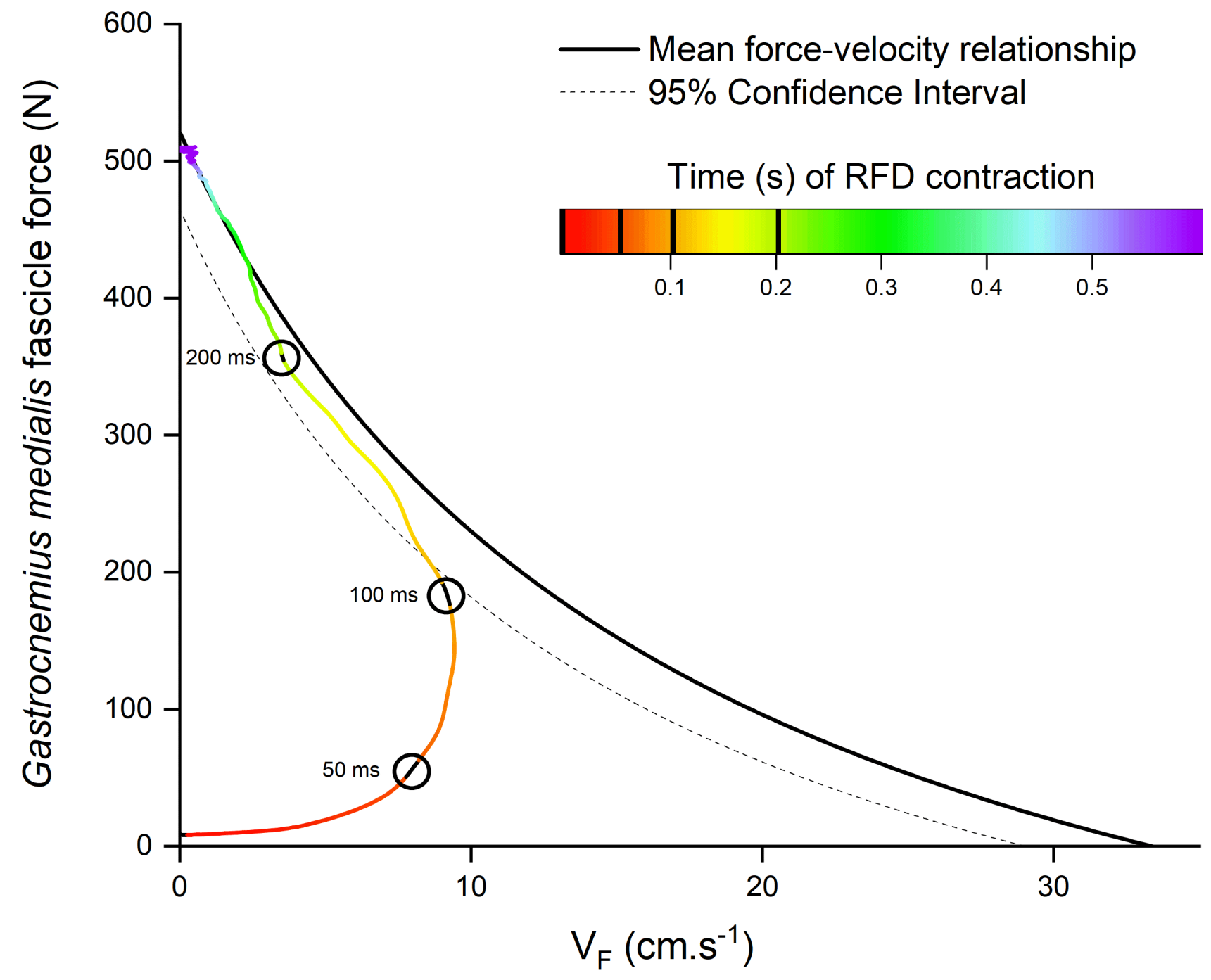

